\title{
Recursos e Práticas de Enfrentamento de Pessoas em Situação de Rua: \\ Uma Revisão Sistemática
}

\author{
Resources and Practices for Coping with Homeless People: A Systematic Review \\ Recursos y Prácticas de Afrontamiento de Personas em Situación de Calle: Una Revisión Sistemática
}

\author{
Carlos Eduardo Esmeraldo Filho \\ Verônica Morais Ximenes \\ Universidade Federal do Ceará (UFC), Fortaleza, CE, Brasil
}

\begin{abstract}
Resumo
O objetivo desse estudo é analisar a produção científica acerca das estratégias de enfrentamento das pessoas em situação de rua em estudos publicados de 2008 a 2019. Foi feita uma revisão sistemática de literatura, a partir das bases Scielo e BIREME, com inclusão de artigos publicados em inglês, português e espanhol. Usou-se o descritor homeless, selecionando-se 36 artigos para análise. Os resultados foram organizados a partir das categorias: recursos para o enfrentamento e práticas de enfrentamento. Em relação aos recursos, os artigos destacam o desenvolvimento de habilidades dessas pessoas e as redes de apoio social disponíveis. Quanto às práticas de enfrentamento, apresentam-se as ações concretas, tanto para se adaptar como para promover transformações. Destaca-se a necessidade de investigar as pessoas em situação de rua no sentido de fortalecer estratégias de enfrentamento.
\end{abstract}

Palavras-chave: enfrentamento, sem-teto, problemas sociais, revisão sistemática.

\begin{abstract}
The aim of this paper is to analyze the scientific production on coping strategies of homeless in studies published from 2008 to 2019. A systematic literature review was carried out, based on the Scielo and BIREME databases, with the inclusion of papers published in English, Portuguese and Spanish. Thirty-six papers were selected for analysis, after using the descriptor homeless. The results were organized based on two categories: resources for coping and coping practices. With regard to resources, papers refer to skills development and social support networks. About the coping practices, it is presented concrete actions, both to adapt and to promote transformations. The need of investigate homeless people is highlighted, in order to strengthen coping strategies.
\end{abstract}

Keywords: coping behavior, homeless, social issues, systematic review. 


\section{Resumen}

El objetivo de este artículo es analizar la producción científica sobre las estrategias de afrontamiento de las personas en situación de calle. Se realizó una revisión sistemática de la literatura, basada en las bases de datos Sielo y BIREME, con la inclusión de artículos publicados en inglés, portugués y español, entre 2008 y 2019. Se utilizó el descriptor homeless, seleccionando 36 artículos para análisis. Los resultados se organizaron en función de dos categorías: recursos para afrontamiento y prácticas de afrontamiento. Con respecto a los recursos, los resultados apuntan el desarrollo de habilidades de estas personas y las redes de apoyo social disponibles. En cuanto a las prácticas, se presentan acciones concretas, tanto para adaptar como para promover transformaciones. Se destaca la necesidad de investigar a las personas en situación de calle para fortalecer las estrategias de afrontamiento.

Palabras clave: enfrentamiento, sin vivienda, problemas sociales, revisión sistemática.

\section{Introdução}

A população em situação de rua é geralmente referida na literatura como estando em condição de privação, sofrimento, violência e não garantia de direitos básicos. A Política Nacional da População em Situação de Rua (Decreto $n^{\circ}$ 7.053, 2009), por exemplo, define essa população referindo-se à pobreza extrema, à falta de moradia regular e à fragilidade de vínculos. Paralelo ao enfoque da carência, existe também uma representação pejorativa dessas pessoas, que geralmente são vistas como mendigos e criminosos (Lima, 2018).

No entanto, apesar da condição de vida precária, alguns estudos enfatizam as potencialidades dessas pessoas. Nesse sentido, Schuch e Gehlen (2012) referem- se à definição de população em situação de rua defendida pelo Movimento Nacional da População de Rua (MNPR), que destaca a solidariedade, luta pelos direitos e por dignidade. A rua, para esses autores, é não somente lugar de carência, mas também de criatividade e luta. Dessa forma, o pesquisador precisa visualizar as múltiplas dimensões do fenômeno, tanto em seu processo de determinação, como também na própria vivência de rua, que é marcada por práticas de produção de relações sociais e simbólicas (Schuch \& Gehlen, 2012).

Dessa forma, apesar da existência de preconceitos e discriminação que caracterizam a situação opressora, as pessoas em situação de rua (PSR) também demonstram potencialidades e capacidades 
de aprendizagem, luta e transformação. Almeida, Ribeiro Jr. e Souza (2016, p. 325), numa pesquisa junto a grupos de dança de rua, compreendem a rua como “[...] espaço-tempo de diversas práticas sociais e quaisquer definições deste espaço têm que levar em consideração a diversidade de perspectivas que o compõe, bem como a pluralidade cultural que o transpassa". Considerar a rua em sua pluralidade cultural e psicossocial demanda perceber espaços de afirmação da vida, de solidariedade, autonomia, criatividade e resistência construídas mediante práticas forjadas na e a partir da rua. Esses elementos apontam para a necessidade de se compreender os potenciais das pessoas que vivem em situação de rua, que se traduzem em práticas de enfrentamento das adversidades.

O conceito de enfrentamento normalmente tem sido compreendido a partir dos estudos de Lazarus e Folkman (1984), referindo-se às respostas de pessoas frente a situações adversas e/ou de estresse com o objetivo de buscar soluções, que podem ser centradas no problema, quando se busca modificar as circunstâncias do problema, ou nas emoções, quando é feito o manejo dos processos cognitivos e emocionais relacionados ao problema. No entanto, essa concepção peca por enfatizar o indivíduo, não abordando ações coletivas de enfrentamento.

Para Sharpe (2015), as pesquisas recentes sobre enfrentamento e estresse, apesar de contribuírem significativamente para o campo, têm sido limitadas na medida em que ignoram os aspectos estruturais e socioculturais que determinam as ações de enfrentamento. Propõem, portanto, um modelo sociocultural, de modo que o enfrentamento é reflexo de crenças, experiências e práticas culturais e coletivas, implicando não somente ações individuais, mas também práticas coletivas e uso de fontes de apoio social. No caso das PSR, cabe compreender tanto os aspectos culturais e estruturais que originam suas condições de vida e práticas de enfrentamento, como também, suas ações individuais. Nesse sentido, apesar de compartilharem a condição de pobreza e exposição a diferentes formas de violência, essas pessoas também demonstram riqueza e criatividade no enfrentamento das adversidades cotidianas e na busca pela sobrevivência (Kunz, Heckert, \& Carvalho, 2015).

Considerando, portanto, a necessidade de compreender as potencialidades dessas pessoas e práticas 
que se configuram como ações de enfrentamento, o objetivo dessa pesquisa é analisar a produção científica acerca das estratégias de enfrentamento das pessoas em situação de rua em estudos publicados de 2008 a 2019.

\section{Metodologia}

Esse estudo define-se como uma revisão sistemática de literatura, considerando artigos científicos publicados no período compreendido entre os anos de 2008 a 2019, em inglês, português e espanhol. A escolha desse período permite captar os estudos publicados a partir do ano em que essa temática passou a ter mais visibilidade no Brasil, tendo em vista que em 2008 realizou-se a primeira contagem nacional das PSR ao mesmo tempo em que se iniciava o debate sobre uma política nacional para inclusão dessa população.

$\mathrm{O}$ primeiro passo consistiu na busca de artigos, que foi realizada mediante o uso do descritor homeless, na Scientific Electronic Library Online (Scielo) e Centro Latino-Americano e do Caribe de Informação em Ciências da Saúde (BIREME), que abarcam periódicos relevantes para as ciências humanas, abrangendo ainda pesquisas latino- americanas. Na pesquisa feita no BIREME (Biblioteca Regional de Medicina), incluímos no filtro as bases Lilacs (Literatura Latino-Americana e do Caribe em Ciências da Saúde) e Index Psi Periódicos Técnico-Científico. Optamos por usar apenas o descritor homeless por abranger todas as nomenclaturas adotadas em português tais como pessoa em situação de rua, moradores de rua $\mathrm{e}$ população de rua, e em espanhol, como habitantes de calle e personas sin hogar. Teses e dissertações, por não serem acessadas pelas bases de dados referidas, não foram analisadas no estudo.

O processo de seleção dos artigos teve como critério de inclusão pesquisas de campo cujos participantes foram adultos que moram nas ruas. Já os critérios de exclusão, foram: estudos que não abordaram recursos e práticas de enfrentamento; pesquisas teóricas; relatos de experiência; pesquisas documentais; pesquisas feitas somente com moradores de abrigos, albergues e centros de acolhimento noturno; pesquisas cujos participantes limitaram-se a crianças e adolescentes e estudos cuja temática central foi o Movimento dos Trabalhadores Sem Teto (MTST). A escolha por investigar adultos que moraram 
efetivamente nas ruas explica esses critérios de exclusão, tendo em vista nem todos os participantes do MTST e moradores de abrigo chegaram a ter a vivência de dormir nas ruas.

Após aplicação dos filtros, que incluíram artigos de 2008 a 2019 e o tipo de publicação (artigo científico), a busca resultou em 666 artigos, sendo 329 na base Scielo, 281 na Lilacs e 56 na Index Psi, conforme Figura 1. Em seguida, procedemos à segunda etapa da pesquisa, ou seja, o processo de triagem de publicações, mediante leitura de títulos, resumos e metodologia. Nesse momento, foram excluídos artigos repetidos e os que se encaixaram nos critérios de inclusão e exclusão. Ao final, restaram 36 artigos para leitura completa e análise.

Figura 1

Ilustração do processo de busca e seleção de artigos

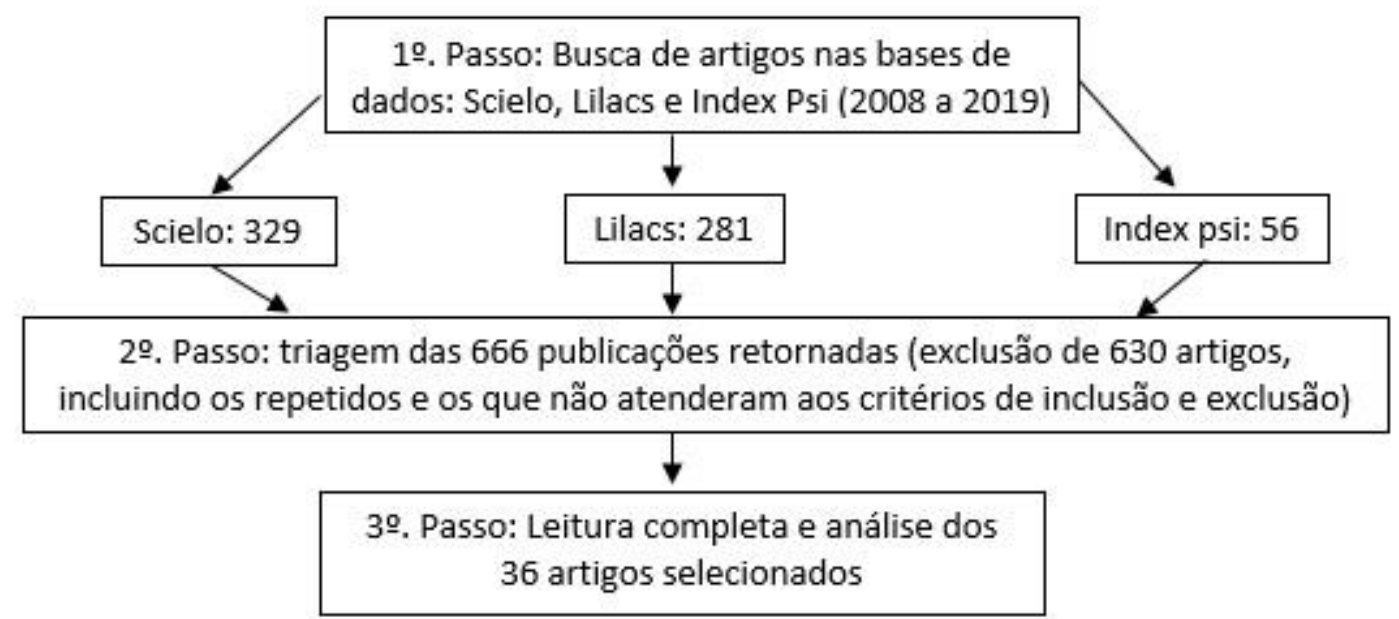

$\mathrm{Na}$ terceira etapa, foi feita uma segunda leitura dos artigos e consequente categorização com uso do software Altas ti versão 5.2, mediante o qual codificamos as categorias Recursos para o enfrentamento, que diz respeito aos recursos disponíveis para as PSR, como, por exemplo, as redes formais e informais de apoio social, e Práticas para o enfrentamento, que se referem às diversas ações concretas realizadas por essas pessoas. Por fim, geramos um arquivo output para cada uma dessas duas categorias, a fim de realizar a análise por categoria. A partir daí, após 
uma caracterização geral dos estudos, as discussões dos resultados se apresentaram com base nessas duas categorias. Todos os procedimentos éticos foram respeitados na elaboração desse estudo.

\section{Resultados e discussões}

Caracterização geral dos estudos

Quanto ao país de realização das pesquisas, há uma maior frequência de produção nacional, com 23 artigos publicados no Brasil e 13 em outros países. Dentre os estudos feitos no Brasil, a concentração maior ocorre no Sudeste (14), enquanto quatro foram feitos nos estados do Sul, quatro no Nordeste e um na região Norte. Quanto à área de formação do primeiro autor, predominam estudos relacionados à Saúde e às Ciências Humanas e Sociais, especialmente de Psicologia (13), Enfermagem (sete) e

Tabela 1

Frequência de artigos com relação aos temas centrais abordados

\begin{tabular}{cc}
\hline TEMAS CENTRAIS & QUANTIDADE \\
\hline Modos de vida/estratégias de & 12 \\
sobrevivência & 9 \\
Sínculos sociais/afeto/redes de apoio & 5 \\
Gênero/mulheres & 5 \\
Uso de drogas & 3 \\
Condições de vida e necessidades & 2
\end{tabular}


básicas

No que diz respeito às categorias utilizadas, a Tabela 2 demonstra uma maior referência acerca das práticas de enfrentamento do que as que se relacionam aos recursos para o enfrentamento. Além disso percebe-se o aumento de publicações a partir do ano de 2010, um ano após a publicação da Política Nacional para a População em Situação de Rua (Decreto ${ }^{\circ}$ 7053, 2009), e um novo acréscimo após 2013. A maior parte dos estudos selecionados são dos últimos cinco anos do período considerado na busca de artigos (2015 a 2019), quando foram publicados 22 artigos, dos quais 16 foram publicados no Brasil e seis em outros países. Já no período de 2008 a 2014, foram publicados 14 artigos, sendo sete pesquisas realizadas no Brasil e sete, em outros países. Esse dado demonstra uma maior visibilidade e interesse acadêmico em estudar essa população nos últimos anos, especialmente no Brasil.

Tabela 2

Ano de publicação e frequência de artigos publicados por categoria

\begin{tabular}{cccc}
\hline Ano & $\begin{array}{c}\text { Recursos para } \\
\text { enfrentamento }\end{array}$ & $\begin{array}{c}\text { Práticas de } \\
\text { enfrentamento }\end{array}$ & TOTAL \\
\hline 2008 & 1 & 0 & 1 \\
2009 & 1 & 0 & 1 \\
2010 & 3 & 1 & 4 \\
2012 & 0 & 2 & 2 \\
2013 & 1 & 0 & 1 \\
2014 & 2 & 3 & 5 \\
2015 & 4 & 4 & 8 \\
2016 & 0 & 2 & 2 \\
2017 & 1 & 1 & 2 \\
2018 & 1 & 3 & 4 \\
2019 & 1 & 5 & 6 \\
TOTAL & 15 & 21 & 36 \\
\hline
\end{tabular}


Os estudos demonstram o predomínio de métodos qualitativos (33), enquanto dois estudos apresentaram abordagem quali-quantitativa e apenas um se apresentou como exclusivamente quantitativo. Desse modo, entrevistas individuais e observação participante foram os instrumentos mais utilizados, além do uso de fotografias, desenho e entrevistas filmadas. Quanto aos instrumentos quantitativos, foram usadas Fichas de Avaliação Social e de Avaliação Psicológica, Questionário de Qualidade de Vida e Questionário de Saúde Geral.

\section{Recursos para o enfrentamento.}

Apenas sete artigos utilizam a expressão enfrentamento nos seus estudos, sem, no entanto, definir o termo, geralmente se referindo a enfrentamento das dificuldades. Os demais tratam dos recursos e práticas para sobreviver, lidar com as condições de vida e modificá-las. Sobre as potencialidades, Cabrera (2019) entende que a frequente visão de desafiliação que se possui das PSR impede de ver a capacidade de criar vínculo e reconhecê-las como sujeitos ativos, que transformam lugares, criam representações e assumem responsabilidades.

A vida na rua possibilita também aprendizagens, ensinamentos e transformações. As discussões de Jesus e Menezes (2010) levam a crer que a experiência de viver na rua promove transformações na vida dos indivíduos, na medida em que possibilita o empoderamento psicológico, a resiliência e o desenvolvimento de certas competências, como a de lidar com as questões da vida na rua, resolver conflitos interpessoais e solucionar problemas. Já Alvarez, Alvarenga e Della Rina (2009) desenvolveram a estratégia do encontro transformador, que é definido como aquele que desperta as potencialidades dos envolvidos, ocasionando a "retomada do rumo de suas existências" (p. 260). Para isso, as autoras promoveram o encontro de uma professora aposentada e duas pessoas em situação de rua, cujo vínculo construído possibilitou o despertar da vontade de buscar novas possibilidades de existência.

Pedemonte (2008) demonstra as transformações ocorridas num grupo de seis pessoas facilitado por um sociólogo e uma psicóloga de uma fundação atuante em Santiago-Chile. Nesse grupo, se 
construiu um processo de validação intersubjetiva, de modo que, para enfrentar a invisibilidade social e a indiferença do Estado e da sociedade, eles passaram a tratar um ao outro com respeito, afeto, empatia e solidariedade, que funcionou como o contraponto ao abandono e solidão. Dessa forma, eles passaram a reconhecer seus direitos e a se perceber como capazes de diálogo e de ação, aptos a transformar suas vidas individuais e também a sociedade. Resultados semelhantes foram encontrados por Silva e cols. (2018), que destacaram uma representação positiva de si mesmo junto aos participantes da pesquisa, os quais se reconheceram como capazes de transformar suas vidas e enfrentar o estigma social

Um recurso importante para o enfrentamento são as redes de apoio social disponíveis. Apesar de serem comuns casos de agressões entre as PSR, existe também uma rede de relações, de modo que são construídos novos laços sociais, que, segundo Flores, Contreras, Hernández, Levicoi e Vargas (2015), eles não desejam romper. Nesse aspecto, para Vernaglia, Vieira e Cruz (2015), os novos laços se assemelham a uma família, implicando em solidariedade e pactuações menos hierárquicas entre homens e mulheres, a fim de compartilhar comida, crack, apoio e proteção.

No entanto, essas relações informais de solidariedade não são as únicas fontes de apoio existentes na rua. Donoso, Bastos, Faria e Costa (2013) referem-se aos recursos governamentais e não-governamentais, incluindo a caridade. Já Galvani e Barros (2010) consideram que há uma rede complexa de relações e interdependência que vão além da mera assistência, não gerando dependência. Seria uma rede assistencial que não significa necessariamente assistencialismo, incluindo governo, associações, a Igreja, a praça, as relações familiares, a cultura e o trabalho. As autoras discutem, ainda, estudos que mostram que o pertencimento a um grupo religioso pode funcionar como fator de proteção ao uso de droga e ajudar o indivíduo a parar de consumir.

Sobre o apoio governamental, os artigos geralmente apresentam os programas existentes e problematizam os gargalos e desafios relacionados às políticas públicas voltadas às PSR. Castillo (2017) refere-se aos serviços-dia, albergues, programas de redução de danos, e outros, mas aponta a falta de ações integradas para o tratamento da dependência de uso de drogas e para geração de emprego e renda na Colômbia. 
No Brasil, De Tilio e Oliveira (2016) apontam para o escasso investimento do Estado, pouca qualificação dos profissionais, bem como as limitações no serviço Consultório na Rua, pela insuficiência de recursos e profissionais. Costa e cols. (2015), por sua vez, destacam que as políticas de segurança pública partem de uma lógica higienista, na medida em que as ações tendem a proteger os demais cidadãos de uma suposta ação nociva das PSR. Por fim, problematizam a relação das participantes com os equipamentos assistenciais, que reforçam a dependência e a fixação delas na rua.

No único estudo que aborda as relações de contato corporal entre agentes sociais e moradores de rua, Cefaï (2010) destaca a importância do toque, aperto de mãos, contato olho no olho, do cheiro e dos cuidados oferecidos pelos profissionais, relacionados a banho e higiene. Esses contatos são considerados, pela equipe de trabalhadores, como momentos de aproximação e de avaliação, tendo efeito simbólico de acolhimento e aproximação e revelando-se como instrumentos de cuidado às PSR.

No aspecto propositivo, os artigos destacam a necessidade de interdisciplinaridade, intersetorialidade, articulação de redes (Caravaca-Morera \& Padilha, 2015b), bem como de atender às especificidades das PSR, que possuem características diferenciadas em relação às pessoas com residência fixa (Aguiar \& Iriart, 2012). A esse respeito, Rosa e Brêtas (2015) enfatizam a necessidade de atender às peculiaridades das mulheres e fortalecer as redes de apoio formais e informais. Farias, Rodrigues, Marinho e Nogueira (2014) referem-se à compreensão da saúde, por parte das PSR, como um instrumento para a realização das atividades diárias, de modo que manter o corpo saudável e forte é um constante desafio para essa população e também para as políticas públicas de saúde. Nesse sentido, Moquillaza-Risco, León, Dongo e Munayco (2015), considerando a alta prevalência de doenças crônicas e de transtornos mentais, enfatizam a necessidade de expansão de programas sociais para a garantia de direitos e fortalecimento da cidadania das PSR.

Ainda referindo-se às políticas públicas, para Castillo (2017), as ações devem incidir sobre os condicionantes da situação de rua, incluindo pobreza, desigualdade, iniquidade, mas também atuar concretamente com o fato de morar e habitar as ruas. A proposta é pensar em 
ações macro e micro a partir da questão da determinação social da saúde e criar mecanismos de participação social e empoderamento comunitário e de recursos humanos para trabalhar em dois eixos: prevenção e mitigação de casos novos; e intervenção e controle dos casos já existentes. Já Rodrigues, Lima e Holanda (2018) refletem sobre a necessidade de formação dos profissionais, tendo em vista a reprodução de estigma existente e que impacta nos serviços e nas intervenções. Seria urgente reconhecer as potencialidades dos sujeitos, a fim de que eles se reconheçam de uma maneira que possam emergir novos personagens. Por fim, o estudo de Panadero-Herrero e Munoz-Lopes (2014), ao encontrarem diferenças nas características das pessoas em função do tempo de situação de rua, concluem que esse fato deve ser levado em conta no momento de planejar e executar intervenções voltadas a essa população, considerando sempre $o$ fomento à autonomia.

\section{Práticas de enfrentamento.}

Nessa dimensão, são analisadas as práticas realizadas pelas PSR para se adaptar e sobreviver na rua, resistir às violências e violações ou para desenvolver projetos de vida, seja permanecendo ou buscando sair da situação de rua. Nesse aspecto, Donoso e cols. (2013) dedicam uma categoria de análise às formas de enfrentar a realidade, enfatizando a busca pela sobrevivência para suprir as necessidades, o uso de álcool e drogas, o trabalho formal ou informal e a mendicância. Já Kunz e cols. (2014) utilizam os conceitos de táticas e modos de vida a fim de analisar as ações individuais e coletivas das PSR, que reinventam as práticas de ocupação do espaço público. Dessa forma, os resultados revelam algumas táticas utilizadas pelas PSR, que incluem: alimentação, correria, regras, relação com a cidade, incluindo igrejas, comerciantes e segurança, banho, pertences, trabalhos etc.

A respeito das práticas de enfrentamento à situação de rua, Holanda (2019) destaca as expressões sistema da rua e se virar, utilizadas pelo participante da sua pesquisa. O sistema da rua diz respeito às experiências negativas vividas na rua, caracterizadas como difíceis, incluindo privações, exclusão, violência e riscos, traduzindo-se num modo de organização especifico, ao qual o morador de rua é obrigado a se submeter. Já o se virar corresponde às ações necessárias para se adaptar ao sistema, implicando em 
aprendizagem de certas habilidades e a criatividade para enfrentar e se afastar do sofrimento (Holanda, 2019). Remete, portanto, à ideia de não passividade, de ser um sujeito ativo para garantir recursos, incluindo obter comida, roupa, água; cozinhar; preparar o local de dormir; caminhar e conhecer espaços e atores; obter bicos; e enfim construir uma rede de relações (Holanda, 2019). Dentre as práticas relativas ao se virar, Holanda (2019) destaca o ato de manguear e de beber cachaça para enganar a fome, que precisa ser feito da maneira o mais discreta possível, a fim de evitar a repressão de policiais, que costumam derramar a bebida quando flagram pessoas bebendo no espaço público. O uso da rede de relações também é uma forma de enfrentamento, que pode acontecer para conseguir alimentos ou bebida. Por fim, Holanda (2019) reflete que a habilidade de se virar na rua é uma forma de não ser capturado pelo sistema da rua, caracterizando-se pela ação criativa do indivíduo, que busca novas formas de viver e habitar na rua. Nessa busca, ainda que ocorra no âmbito micropolítico, se constitui um modo de vida que se configura como um processo de organização política (Holanda, 2019).

Sobre as formas de ganhar dinheiro nas ruas, Kunz e cols. (2014) referem-se à expressão correria, que é uma tática que implica em conseguir dinheiro, mediante o manguear, por exemplo, mas também atos criminosos. Com relação ao trabalho, Fiorati, Carretta, Kebbe, Cardoso e Xavier (2017) encontraram relatos de inserção em atividades de baixa renda sendo que os participantes acima de 40 anos relataram alguma ocupação profissional, como pintor e pedreiro, enquanto os mais jovens limitam-se a relatar atividades informais (tráfico de drogas, reciclagem, vigia de carro, etc). Resultados semelhantes foram encontrados no estudo de Schenck, Roman, Erasmus, Blaauw e Ryan (2017), na medida em que $65 \%$ realizam bicos, $30 \%$ coleta de lixo, $22 \%$ viviam de auxílio governamental, $19 \%$ tinham emprego formal e $2 \%$ praticavam comércio ambulante.

Para Flores e cols. (2015), as PSR que já chegaram na rua após adultos conseguem identificar atividades laborais do passado como uma ocupação significativa. $\mathrm{Na}$ rua, o trabalho é visto como algo importante, pois os mantém longe do uso de drogas e permite o sustento da família. No entanto, em alguns casos, o desejo de trabalhar aparece distante da realidade, devido à 
incompatibilidade com a vida atual, restando a ilusão de que um trabalho futuro resolverá os problemas, permitindo a recuperação do vínculo com a família, mas por outro lado não realizam ações concretas para alcançar (Flores e cols., 2016). Nesse aspecto, é importante destacar que a dificuldade de se inserir no mercado de trabalho e retomar o vínculo familiar é resultado de um processo de determinação estrutural, e não da falta de esforço ou dedicação individual.

Os que trabalham e obtém renda conseguem comprar comida, no entanto há doações de alimentos na rua, por instituições e restaurantes (Andrade, Costa, \& Marquetti, 2014). São comuns também o uso de restaurantes populares, práticas de cozinhar nas ruas e o ato de catar comida no lixo (Kunz e cols., 2014). No que se refere às táticas para dormir, há relatos de medo de dormir nas ruas, devido aos perigos relacionados à criminalidade e uso e tráfico de drogas (De Tilio \& Oliveira, 2016), de maneira que há uma busca de proteção como dormir em grupo, dormir com "olho aberto" ou em locais com postos policiais (Aguiar \& Iriart, 2012) ou ainda dormir durante o dia para ficar acordado à noite (Kunz e cols. 2014).

Possuir cães nas ruas foi apontado como um modo de enfrentamento por
Cabrera (2019) e Baltar e Garcia (2019). Para o primeiro, além da importância dos laços, ter cães na rua estimula a responsabilidade de cuidar. Já Baltar e Garcia (2019) enfatizam, além do bemestar promovido na relação de amizade, o elemento de proteção e o papel intermediador do cão como repercussões positivas para as PSR. Dessa forma, os cães protegem os donos, latindo na ocasião de uma abordagem violenta da polícia ou ficando acordado enquanto seu dono dorme. O papel intermediador refere-se ao fato de que os cães atraem a atenção de pessoas que oferecem ajuda, produzindo, assim, uma nova forma de olhar para o indivíduo em situação de rua, que passa a ser visto não como coisa, mas como pessoa, "um ser dotado de emoções refletidas em suas ações para com os animais" (Baltar \& Garcia, 2019, p. 203).

As PSR buscam ocupar o espaço da cidade a fim de garantir a sobrevivência e satisfazer suas necessidades. Estudo de González, Blandon, Quiceno, Giraldo e Forero (2014) investigou pessoas que moravam debaixo de uma ponte, nas margens de um riacho, o qual fornecia as mínimas condições de sobrevivência, sendo possível descansar, se alimentar, tomar banho, lavar roupas, consumir álcool e drogas, além das atividades de trabalho 
como reciclagem, guardar carros e venda. Já Kunz e cols. (2014) partem do pensador Michel de Certeau para se referir às PSR como "praticantes ordinários da cidade'", que se caracterizam pela reinvenção de práticas na ocupação do espaço, de modo que os lugares que eram de passagem passam a ser lugares de encontro, mediante uso de prédios abandonados, casas, pontes, viadutos, praças, marquises, entendido por eles como ocupação e não invasão.

Essa compreensão é semelhante à discussão feita por Andrade e cols. (2014), que consideram as PSR como transgressores na medida em que a vida na rua implica na transformação do espaço público da cidade, numa reinvenção do uso do espaço e das relações sociais na rua. Assim, eles revertem as concepções de público e privado, na medida em que a vida íntima acontece no espaço público. De uma maneira geral, em comparação à vida vinculada a um bairro ou comunidade, as PSR rompem com as regras de convivência, construindo novas normas, códigos e regras que precisam ser respeitados. Essa transgressão também se constata pela ideia de que a ida e o viver na rua implica numa ruptura com o mercado e com um padrão de vida exigido, criando-se novos códigos de vida para garantir a sobrevivência (Aguiar \& Iriart, 2012). Além disso, segundo Costa e cols. (2015), as PSR constroem novas referências e ressignificam as referências anteriores.

Nobre, Moreno, Amorim e Souza (2018), em estudo realizado com mulheres em situação de rua, identificam ações que se configuram como resistência, conceito entendido como possibilidade de mudança e de criação, e não como mera reação. Apontam, por um lado, redes de proteção, solidariedade e mangueio, e, por outro lado, ações coletivas, de militância e luta, com inserções em movimentos sociais. Nesse sentido, essas autoras compreendem que as mulheres entrevistadas subvertem o modo capitalístico que exclui e violenta seus corpos, mediante a recusa à lógica consumista, o nomadismo, a arte, e a ocupação de espaços e territórios.

Diante da questão do desrespeito e da violência, conforme já abordada anteriormente, também há formas de enfretamento por parte das PSR. Kunz e cols. (2014), por exemplo, referem-se a estratégias de segurança, como o uso de objetos como barras de ferro, facas, facões, e a delimitação de território, com alguém no comando para garantir a segurança. Já no caso do desrespeito, Graaf (2012) percebeu uma atitude de esquiva de alguns 
participantes que, para ele, pode ter sido para fugir do estigma e preservar a sua autoestima. Dessa forma, há casos em que a pessoa esconde as marcas corporais, o odor, a sujeira, que significa esconder a condição social de morar na rua, para evitar o desrespeito. Esse autor compreende que as PSR não lutam apenas pela sobrevivência, mas também contra as condições precárias que estão inscritas no corpo e contra o desrespeito social. Cuidar da aparência ajuda a reduzir o estigma, mas há também os que usam o mau cheiro de propósito como forma de afastar pessoas, demarcar territórios ou se proteger contra a violência (Aguiar \& Iriart, 2012; Cefaï, 2010).

Alguns artigos referem-se ao uso de drogas não somente como sendo prejudicial, mas também como forma de lidar com problemas. Rodríguez (2010) destaca o consumo de droga como forma de socialização dentro de um grupo social, pois além do ato de usar drogas coletivamente, há também a possibilidade de participar de outras atividades como praticar esportes ou jogos de cartas. $\mathrm{Na}$ compreensão de Medeiros (2019), tendo em vista que a bebida é compartilhada e passada de mão em mão, há um ritual marcado pelo simbolismo que a bebida adquire para os moradores de rua, na medida em que contribui para a sociabilidade e para relações de reciprocidade, mediando os vínculos sociais. Dessa forma, se por um lado a droga estigmatiza e rotula, por outro lado é um objeto simbólico que possui uma lógica social e normativa, orientando expectativas e comportamentos dentro do grupo. Para De Tilio, Vidotto e Galego (2015) e Costa e cols. (2015), o uso de droga ajuda a lidar com as experiências dolorosas na rua, tais como frio, dor, fome, sono, humilhação etc. Já Caravaca-Morera e Padilha (2015a) compreende que a droga aprisiona as pessoas na rua, tendo em vista que impede a realização de outros projetos de vida, mas, por outro lado, é associado a uma ideia de libertação, prazer e anestesia das dores. Outro motivo para o uso de drogas é manter-se em alerta durante a noite para fugir da violência ou exagerar no uso até apagar e conseguir dormir. Essa é a análise feita por Campos e MorettiPires (2018), que citam estudos norteamericanos que mostram que, devido à violência sofrida antes da ida para a rua, a população LGBT que mora na rua usa drogas com frequência maior do que as demais PSR.

Dois estudos abordam essa questão a partir da perspectiva familiar. CaravacaMorera (2015b) e De Tilio e Oliveira 
(2016) concluem que o uso de drogas é solução para compensar as ausências paternas e maternas, ou outras perdas familiares e, na falta de outros recursos disponíveis, para enfrentar a tristeza e o fato de estarem sozinhos. A partir dessas análises, percebe-se que a droga serve ao mesmo tempo para ajudar a tolerar as adversidades, entretanto contribui para intensificar a estigmatização e dificultar a saída da situação de rua, na medida em que muitos falam que para enfrentar essa condição é necessário também enfrentar o uso abusivo de drogas. Nesse sentido, Rodrigues e cols. (2018) citam o caso de um participante que, na luta contra o abuso de substâncias, esteve internado 17 vezes em comunidades terapêuticas, alternando com períodos na rua.

O uso de drogas também tem consequências para a higiene do corpo e o cuidado com a saúde, que no geral já é complicado. No que diz respeito ao banho, fazem uso de banheiros públicos, chuveiros de praias, praças, cais, bares, padarias, desde que antes sejam criados vínculos, e em lugares onde eles vendem materiais coletados ou em equipamentos filantrópicos (Andrade e cols., 2014). Sobre o cuidado com a saúde, geralmente eles buscam o serviço de saúde em último caso, preferindo recorrer à automedicação, uso de droga para esquecer das dores, ajuda mútua, remédios caseiros, chás (De Tilio \& Oliveira, 2016; González e cols., 2014). Também há os que, no caso de algum problema de saúde, recorrem à religiosidade e ao recolhimento em algum lugar até melhorar. A justificativa para não procurar serviço de saúde relaciona-se à falta de tempo, pois precisam buscar a sobrevivência, e à ineficácia do tratamento, pois eles teriam que retornar as ruas e não poderiam aderir corretamente ao medicamento nem teriam como cuidar da saúde (Aguiar \& Iriart, 2012). O autotratamento também foi apontado como a forma mais comum de cuidado da saúde no estudo de Vale e Vecchia (2019), os quais se referem ao autocuidado em ferimentos, à automedicação, ao uso de plantas medicinais, proveniente de saberes da zona rural ou de crenças familiares e aos conselhos de amigos e conhecidos.

A procura pelo serviço de saúde somente em casos graves não significa que a saúde seja negligenciada, pois é vista como um recurso para a realização das atividades do dia a dia, a fim de satisfazer as necessidades, por isso deve ser conservada. Para os participantes do estudo de Gonzáles e cols. (2014), estar são é 
estar em boas condições e manter costumes de higiene e cuidado com a alimentação e moradia. A saúde espiritual é compreendida a partir das relações afetivas com a família e com os outros, boa autoestima, ter consciência limpa.

Uma temática de grande importância, mas pouco estudada, refere-se às questões de gênero nas ruas. Além das dificuldades enfrentadas pela população LBGT, ser mulher também implica formas diferenciadas de enfrentamento, tendo em vista o sexismo e o risco de sofrer violência sexual. Segundo Costa e cols. (2015), diferentes estratégias de proteção são utilizadas, tais como se vincular a um parceiro homem ou se isolar e viver na solidão. Na pesquisa de Rosa e Brêtas (2015), os resultados foram diferentes, na medida em que as mulheres ouvidas não relataram entrar num relacionamento por proteção, afirmando relacionar-se quando se sentiam atraídas, quando desejavam, subvertendo a ideia de que são frágeis e dependentes e enfatizando a facilidade de trocar de parceiro pela quantidade maior de homens vivendo nas ruas. Para os autores, elas se tornaram menos tolerantes à violência dos parceiros, se comparado a quando tinham o medo de perder o lar doméstico. Já Sanchotene, Antoni e Munhós (2019) destacam que as mulheres recorrem, como forma de proteção, além da vinculação a um homem, à união com outras mulheres.

Já com relação à prostituição, ela faz parte da rotina das participantes da pesquisa de Vernaglia e cols.(2015), no entanto há um cuidado para delimitar o que corresponde ao trabalho e o que se refere às relações de afeto. Há, no entanto, um certo silêncio quanto ao tema, e algumas mulheres não revelam a prostituição, seja porque os parceiros não sabem seja para protegê-los de situações constrangedoras.

Surgiram também análises sobre projetos de vida em alguns artigos, que revelam expectativas positivas para $\mathrm{o}$ futuro, como voltar para sua cidade, parar de usar droga e trabalhar, e negativas, que incluem desânimo e desesperança quanto a mudar a realidade (Donoso \& cols., 2013). Nesse mesmo sentido, Fiorati e cols. (2017) destacam relatos que revelam desejo de ter um trabalho e uma casa e mudar de vida, todavia acompanhado de desesperança. Esses projetos também foram encontrados por Flores e cols. (2015), incluindo a vontade de retomar os vínculos familiares, no entanto a influência do ambiente e o uso de drogas são considerados obstáculos fortes. Também foram encontrados planos para se manter nas ruas e nos empregos informais para 
continuar sustentando o vício sem precisar roubar ou furtar (Andrade e cols., 2014).

A análise dos artigos selecionados demonstram a complexidade dessa realidade, sendo necessário esforços para avaliar e criar novas estratégias de enfrentamento, considerando, por exemplo, o tempo de vivência nas ruas, tendo em vista que, para Andrade e cols. (2014), há pessoas que constroem um hábito nas ruas e possuem dificuldades de se reacostumar com a residência fixa, preferindo a liberdade das ruas do que o conforto e a proteção da casa. Coerente com essa reflexão, Graeff (2012) conclui que a reinserção social não é uma questão de escolha, pois somente se torna possível se a pessoa "tirar a rua do corpo". Isso é difícil, pois o recurso de esconder a sujeira, o odor, etc., não apaga facilmente as experiências de violência. Ao concluir, o autor arremata: "Uma vez incorporadas, essas experiências de privação de direitos e de degradação moral se impõem contra toda tentativa de reabilitação física e psíquica” (Graeff, 2012, p. 770).

Em suma, são múltiplas as práticas de enfrentamentos discutidas. Apesar de muitas delas limitarem-se à satisfação das necessidades básicas e a sobrevivência cotidiana, a PSR também luta contra o desrespeito, ou seja, por reconhecimento social, e essa luta é política. Também foram identificadas referências a ações de resistência e à organização política da população em situação de rua nas últimas décadas, que resultou no surgimento do MNPR em 2004 (Pimenta, 2019). Ademais, Nobre e cols (2018) compreendem que foi a partir da luta e pressão do MNPR que o Estado incluiu a PSR na agenda de debate do Governo Federal, culminando no lançamento da Política Nacional para População em Situação de Rua em 2009. É importante ainda destacar as reflexões dessas autoras, que compreendem que a "macro e a micropolítica são vistas aqui como duas faces de um mesmo processo, que embora nem sempre articuladas, não se contrapõem" (Nobre e cols, 2018, p. 4).

\section{Considerações finais}

Os artigos analisados nessa revisão sistemática revelaram diversos recursos e práticas de enfrentamento, que demonstram que, apesar da pobreza e violência, existem redes de apoio, vínculos afetivos e solidariedade em torno das pessoas em situação de rua. Além disso, as discussões efetivadas em pesquisas de 
campos enfatizam a necessidade de olhar para os recursos, habilidades e atitudes das pessoas em situação de rua, que se apresentam como sujeitos criativos cujas ações vão além da mera adaptação ou sobrevivência. Ainda que os estudos não tenham aprofundado especificamente $\mathrm{o}$ conceito de enfrentamento junto às pessoas em situação de rua, coletaram informações que apresentam os recursos e as práticas para enfrentar o cotidiano adverso.

$$
\text { Enfatizar elementos de }
$$

enfrentamento não implica negar as condições precárias e as intensas privações dessa população, as quais são cotidianamente enfatizadas nas pesquisas, discursos governamentais e pela sociedade em geral. No entanto, existem também elementos que indicam capacidades, por parte das pessoas em situação de rua, de realizar ações individuais e coletivas de enfrentamento. Nesse aspecto, essa revisão revelou tanto ações meramente adaptativas, focadas nas emoções, na dimensão individual da mudança ou voltadas para garantir a sobrevivência, como também ações e movimentos coletivos que buscam resistir às situações opressoras, transformar as condições de vida e problematizar essa realidade como sendo resultado da estrutura social capitalista excludente. A rede de relações que cerca as pessoas em situação de rua também originam redes políticas, como, por exemplo, as que são lideradas pelo Movimento Nacional da População de Rua.

Desse modo, considerando que a população em situação de rua tem sido reconhecida pela sua complexidade e heterogeneidade, não causa espanto encontrar diferentes estratégias de enfrentamento, coexistindo práticas individuais, tendo em vista e necessidade da PSR sobreviver e buscar melhorar a condição de vida, com práticas coletivas, mais ou menos organizadas, num movimento de luta por respeito aos direitos dessa população.

É importante ressaltar que a materialidade das condições de vida nas ruas e a constante exposição violências, desrespeito e estigma tem implicações psicossociais, como autoculpabilização e inferiorização, que podem prejudicar o enfrentamento, no entanto não se trata de um processo irreversível. Dessa forma, deve-se falar no múltiplo processo de enfrentamento, pois há a necessidade tanto de combater os estigmas, como também lutar contra as consequências devastadoras da vida nas ruas e em prol da transformação social.

Essa revisão traz contribuições no 
sentido de compreender o conceito de enfrentamento de maneira abrangente e, por consequência, enfatizar recursos e potenciais que podem ser explorados e fortalecidos como estratégia de enfrentamento das pessoas em situação de rua, subsidiando ações governamentais e não governamentais. No entanto, vale lembrar que essas ações devem considerar o processo estrutural econômico, social e político, de determinação da pobreza e situação de rua. Salienta-se, como recomendação para novas pesquisas, a necessidade de aprofundar o conceito de enfrentamento no contexto das PSR.

\section{Referências}

Aguiar, M. M., \& Iriart, J. A. B. (2012). Significados e práticas de saúde e doença entre a população em situação de rua em Salvador, Bahia, Brasil. Cadernos de Saúde Pública, 28(1), 115-124. doi: http://dx.doi.org/10.1590/S0102311X2012000100012

Almeida, S. F. de, Ribeiro Junior, D., \& Souza, R. P. (2016). A rua como espaço e tempo de possibilidades educativas. Revista Inter Ação, 41(2), 323-336. doi: https://doi.org/10.5216/ia.v41i2.40 $\underline{776}$

Alvarez, A. M. D. S., Alvarenga, A. T. D., \& Della Rina, S. C. D. S. (2009). Histórias de vida de moradores de rua, situações de exclusão social e encontros transformadores. Saúde e sociedade, 18(2),259-272. doi: https://dx.doi.org/10.1590/S010412902009000200009

Andrade, L. P., Costa, S. L. D., \& Marquetti, F. C. (2014). A rua tem um ímã, acho que é a liberdade: potência, sofrimento e estratégias de vida entre moradores de rua na cidade de Santos, no litoral do Estado de São Paulo. Saúde $e$ Sociedade, 23(4), 1248-1261. doi: http://dx.doi.org/10.1590/S010412902014000400011

Baltar, J. G. D. C., \& Garcia, A. (2019). Pessoas em situação de rua e seus cães: fragmentos de união em histórias de fragmentação. Gerais: Revista Interinstitucional de Psicologia, 12(2), 191-209. doi: http://dx.doi.org/10.36298/gerais20 19120202

Cabrera, L. P. (2019). 'Así ocupo un lugar'. Situación de calle y las otras formas de habitar la ciudad en Chile y Uruguay. Estudios atacameños, 63, 105-130. doi: http://dx.doi.org/10.22199/issn.071 8-1043-2019-0027

Campos, D. A., \& Moretti-Pires, R. O. (2018). Trajetórias sociais de gays e lésbicas moradores de rua de Florianópolis (SC), 2016. Revista Estudos Feministas, 26(2), e45995. doi: https://dx.doi.org/10.1590/18069584-2018v26n245995

Castillo, L. A. D. (2017). Determinantes sociales del fenómeno de habitabilidad de calle en Bogotá 
DC Una aproximación desde la salud urbana. Medicina $U P B, 36(1)$, 51-58. doi: 10.18566/medupb.v36n1.a07

Caravaca-Morera, J. A., \& Padilha, M.I. (2015a). Entre batalhas e pedras: Histórias de vida de moradores de rua, usuários de CRACK. Revista Hacia la Promoción de la Salud, 20(1), 49-66. doi: 10.17151/hpsal.2015.20.1.4

Caravaca-Morera, J. A., \& Padilha, M. I. (2015b). A dinâmica das relações familiares de moradores de rua usuários de crack. Saúde em debate, 39 (106), 748-759. doi: https://dx.doi.org/10.1590/01031104201510600030015

Cefaï, D. (2010). Provações corporais: uma etnografia fenomenológica entre moradores de rua de Paris. Lua Nova, 79, 71-110. doi: https://dx.doi.org/10.1590/S01 02-64452010000100005

Costa, S. L. D., Vida, C. P. D. C., Gama, I. A., Locatelli, N. T., Karam, B. J., Ping, C. T., Massari, M. G., Paula, T. B. de, \& Bernardes, A. F. M. (2015). Gestantes em situação de rua no município de Santos, SP: reflexões e desafios para as políticas públicas. Saúde e Sociedade, 24(3), 1089-1102. doi: http://dx.doi.org/10.1590/S010412902015134769

De Tilio, R., \& de Oliveira, J. (2016). Cuidados e atenção em saúde da população em situação de rua. Psicologia em estudo, 21(1), 10113 , Doi: http://dx.doi.org/10.4025/psicolestu d.v21i1.27142
De Tilio, R., Vidotto, L. T., \& Galego, P. S. (2015). Medos e expectativas de usuários de drogas em situação de rua. Revista da SPAGESP, 16(2), 75-87. Recuperado de http://pepsic.bvsalud.org/scielo.php ?script=sci_arttext\&pid=S167729702015000200007\&lng=pt\&tlng $=$ pt.

Decreto n 7053 (2009). Presidência da República Federativa do Brasil. Recuperado de http://www.planalto.gov.br/ccivil_0 3/_Ato20072010/2009/Decreto/D7053.htm

Donoso, M. T. V., Bastos, M. A. R., Faria, C. R. D., \& Costa, A. A. (2013). Estudo etnográfico sobre pessoas em situação de rua em um grande centro urbano. Revista Mineira de Enfermagem, 17(4), 894-909. doi: http://www.dx.doi.org/10.5935/141 5-2762.20130065

Farias, D., Rodrigues, I., Marinho, Í., \& Nogueira, L. (2014). Saberes sobre saúde entre pessoas vivendo em situação de rua. Psicologia e Saber Social, 3(1), 70-82. doi: https://doi.org/10.12957/psi.saber.s oc. 2014.10064

Fiorati, R. C., Carretta, R. Y. D., Kebbe, L. M., Cardoso, B. L., \& Xavier, J. J. D. S. (2016). As rupturas sociais e o cotidiano de pessoas em situação de rua: estudo etnográfico. Revista Gaúcha de Enfermagem, 37(spe), e72861. http://dx.doi.org/10.1590/19831447.2016.esp.72861

Flores, M., Contreras, C., Hernández, 
Y., Levicoi, Y., \& Vargas, C. (2015). Ocupación e identidad social en personas en situación de calle de la ciudad de Punta Arenas. Revista Chilena de Terapia Ocupacional, 15(2), 1-16. doi: $10.5354 / 0719-5346.2015 .38159$

Galvani, D., \& Barros, D. D. (2010). Pedro e seus circuitos na cidade de São Paulo: religiosidade e situação de rua. Interface-Comunicação, Saúde, Educação, 14 (35), 767$779 . \quad$ Recuperado de http://www.scielo.br/pdf/icse/2010 nahead/aop2310.pdf

González, M. A., Blandon, D., Quiceno, J. A., Giraldo, Á., \& Forero, C. (2014). Habitar bajo los puentes: vida y muerte; dos formas de comenzar algo. Revista Facultad Nacional de Salud Pública, 32(2), 36-41. Recuperado de Recuperado de

http://www.scielo.org.co/scielo.php ?script=sci_arttext\&pid=S0120386X2014000200005\&lng=en\&tln $\mathrm{g}=$

Graeff, L. (2012). Corpos precários, desrespeito e autoestima: o caso de moradores de rua de ParisFR. Psicologia USP, 23(4), 757775 .

doi: https://doi.org/10.1590/S010365642012000400008

Holanda, J. G. (2019). Se virando no sistema da rua: Moradores de rua, conceitos e práticas. Civitas Revista de Ciências Sociais, 19(1), 28-44. doi: https://dx.doi.org/10.15448/19847289.2019.1.30941

Jesus, M. F. D., \& Menezes, I. (2010).
A experiência de sem-abrigo como promotora de empoderamento psicológico. Análise

Psicológica, 28(3),

527-535.

Recuperado de http://www.scielo.mec.pt/scielo.ph p? script $=$ sci_arttext\&pid $=$ S0870$82312010000300012 \& \operatorname{lng}=$ pt\&tlng $=\mathrm{pt}$.

Kunz, G. S., Heckert, A. L., \& Carvalho, S. V. (2014). Modos de vida da população em situação de rua: inventando táticas nas ruas de Vitória/ES. Fractal: Revista de Psicologia, 26(3), 919-942. doi: https://dx.doi.org/10.1590/19840292/1192

Lazarus, R. S., \& Folkman, S. (1984). Stress, appraisal, and coping. New York: Springer Publishing Company.

Lima, N. P. de M. (2018). Movimento Nacional da População em Situação de Rua do RN: formação política (Dissertação de Mestrado) Universidade Federal do Rio Grande do Norte. Natal, RN, Brasil. Recuperado de: https://repositorio.ufrn.br/jspui/bitst ream/123456789/25092/1/Nathalia PotiguaraDeMoraesLima_DISSER T.pdf

Medeiros, R. P. (2019). Entre as andanças e as travessias nas ruas da cidade: Territórios e uso de drogas pelos moradores de rua. Civitas Revista de Ciências Sociais, 19(1), 142-158.

doi: https://dx.doi.org/10.15448/19847289.2019.1.30759

Moquillaza-Risco, M., León, E., Dongo, M., \& Munayco, C. V. (2015). 
Características sociodemográficas y de salud de los adultos mayores en situación de calle en Lima, Perú. Revista Peruana de Medicina Experimental y Salud Pública, 32 (4), 693-700. Recuperado de http://www.scielo.org.pe/scielo.php ?script=sci_arttext\&pid=S172646342015000400010\&lng=es\&tlng $=\mathrm{es}$

Nobre, M. T, Moreno, N. S., Amorim, A. K. M. A., \& Souza, E. C. (2018). Narrativas de modos de vida na rua: histórias e percursos. Psicologia \& Sociedade, 30, e175636. doi: https://dx.doi.org/10.1590/18070310/2018v30175636

Panadero-Herrero, S., \& Muñoz-López, M. (2014). Salud, calidad de vida y consumo de sustancias en función del tiempo en situación sin hogar. Anales de psicología, 30(1), 70-77. doi: http://dx.doi.org/10.6018/analesps. 30.1.137911

Pedemonte, N. R. (2008). El reconocimiento en el otro: autoafirmación y acción comunicativa en personas en extrema exclusión. Polis (Santiago), 7(20), 105-132. doi: https://dx.doi.org/10.4067/S071865682008000100007

Rodrigues, J. S, Lima, A. F., \& Holanda, R. B. (2018). Identidade, Drogas e Saúde Mental: Narrativas de Pessoas em Situação de Rua. Psicologia: Ciência e Profissão, 38(3), 424436. https://dx.doi.org/10.1590/198 2-37030004912017

Rodríguez, L. B. (2010). Prácticas cotidianas de personas adultas jóvenes que viven en la plaza Zarco (Ciudad de México). Revista Latinoamericana de Ciencias Sociales, Niñez y Juventud,8(1), 411-437. Recuperado de http://www.scielo.org.co/scielo.ph p? script=sci_arttext\&pid=S1692715X2010000100020\&lng=e

Rosa, A. D. S., \& Brêtas, A. C. P. (2015). A violência na vida de mulheres em situação de rua na cidade de São Paulo, Brasil. Interface-Comunicação, Saúde, Educação, 19(53), 275-285. doi: https://dx.doi.org/10.1590/180 7-57622014.0221

Sanchotene, I. P., Antoni, C., \& Munhós, A. A. R. (2019). Maria, Maria: concepções sobre ser mulher em situação de rua. Textos \& Contextos (Porto Alegre), 18(1), 146-160. doi:

http//dx.doi.org/10.15448/16779509.2019.1.29297

Schenck, R., Roman, N., Erasmus, C., Blaauw, D., \& Ryan, J. (2017). Homeless in observatory, Cape Town through the lens of MaxNeef's fundamental human needs taxonomy. Social Work, 53(2), 266287.

doi: https://doi.org/10.15270/53-2568

Schuch, P., \& Gehlen, I. (2012). A 'situação de rua' para além de determinismos: Explorações conceituais. In: A. E. Dornelles, A. E. J. Obst \& M. B. Silva (Org.). A rua em movimento (pp. 11-25). Belo Horizonte, Brasil: Didática.

Sharpe, T. L. (2015). Understanding the sociocultural context of coping for 
African American family members of homicide victims: A conceptual model. Trauma, Violence, \& Abuse, 16(1), 48-59. doi: https://doi.org/10.1177/152483801 3515760

Silva, L. M., Aristizábal, A. I., Gómez, M. C., González, Y. A., Acevedo, C. M., Ortiz,... Y. P., Rodriguez, N., \& Campo, N. M. (2018).

Reconstrucción de experiencias y percepciones propias de jóvenes habitantes de calle. Revista Latinoamericana de Ciencias Sociales, Niñez y Juventud, 16(2), 809-823. doi: https://doi.org/10.11600/1692715x. 16211

Vale, A. R., \& Vecchia, M. D. (2019). "UPA é nós aqui mesmo": as redes de apoio social no cuidado à saúde da população em situação de rua em um município de pequeno porte. Saúde e Sociedade, 28(1), 222-234. doi:

https://dx.doi.org/10.1590/s010412902019180601

Vernaglia, T. V. C., Vieira, R. A. D. M. S., \& Cruz, M. S. (2015). Usuários de crack em situação de ruacaracterísticas de gênero. Ciência
\& Saúde Coletiva, 20(6), 18511859.

doi: https://dx.doi.org/10.1590/141

3-81232015206.11562014

Carlos Eduardo Esmeraldo Filho é psicólogo e mestre em Saúde Pública pela UECE. É também doutorando em Psicologia pela Universidade Federal do Ceará e professor do Centro Universitário Unifanor Wyden.

E-mail: cefilho@gmail.com

ORCID:https://orcid.org/0000-0001-7098$\underline{0460}$

Verônica Morais Ximenes é psicóloga e doutora em Psicologia pela Universidad de Barcelona (Espanha). É também pós doutora em Psicologia pela UFRGS e docente do Programa de Pós Graduação em Psicologia da Universidade Federal do Ceará e Pesquisadora do CNPq PQ-2.

E-mail: vemorais@yahoo.com.br ORCID:https://orcid.org/0000-0003-3564$\underline{8555}$

Submissão: 06/05/2020

$1^{o}$ avaliação: 28/04/2021

Aceite: $12 / 07 / 2021$ 